\title{
Internet Addiction among Students: The Relation of Depression
}

\author{
Dr. Shashi Kala Singh ${ }^{1}$
}

\section{ABSTRACT}

The purpose of this study is to investigate not only the prevalence of internet addiction among the male and female students but, also the relationship between internet addiction and depression. The tools of measurement used are the Young Internet Addiction and Beck Depression Questionnaire. The data was analyzed by t-test and correlation. The results show that prevalence of internet was more in male students than female students. Correlation analysis showed a positive and significant relation between internet addiction and depression.

Keywords: Internet addiction, depression and students.

Internet addiction is a broad concept. The current modes of information and communication technology such as the Computer, the Internet, and mobile phones have changed adolescents' daily life drastically. In addition to being a convenience to people's communication methods, technology unfortunately has negative side-effects. The most frequent negative sideeffect is chronic addiction to technological mediums or excessive human-machine interactions involved. Internet is a technological tool which makes our life easier and has become an indispensable part of it while it's number of user population increases faster each day (Yapici, and Akbayin, 2012). The internet is a new tool that is evolving into an essential part of everyday life all over the world (Nalwa \& Anand, 2003) and its use increases especially among young people. In spite of the widely perceived merits of this tool, psychologists and educators have been aware of the negative impacts of its use, especially the over or misuse and the related physical and psychological problems (Greenfield, 2000). Internet provides a quick and easy way to get the information needed and to communicate with people. However, in addition to these facilities, loss of the control over the use of internet may adversely affect daily activities, emotional status and communication among family members. Loss of control over the use of internet may also be called excessive internet use, pathological internet use, problematic internet use and internet addiction. Internet addiction is characterised by preoccupation with the use of the internet, repetitive thoughts about limiting and controlling the use of the internet, failure to control the desire of access to the internet, continuous use of the internet despite the impairments at various levels of functionality, spending gradually increasing periods of time on the internet,

${ }^{1}$ Associate Professor, University Department of Psychology, Ranchi University, Ranchi (C) 2015 I S Singh; licensee IJIP. This is an Open Access Research distributed under the terms of the Creative Commons Attribution License (http://creativecommons.org/licenses/by/2.0), which permits unrestricted use, distribution, and reproduction in any Medium, provided the original work is properly cited. 
seeking use of the internet in the case of inability to access, and uncontrolled desire to get access to the internet. As is in other addictions, internet addiction is also a major health problem during puberty which is characterised by continuing mental and motor development. The individuals are emotionally and socially highly fragile in this period. Internet has the potential to cause social isolation and hinder development of social interaction skills required for real life situations. The Internet is a modern communication tool, which basically can change and makes easier the ways of communication between people, it eliminates geographical barriers and shortens real distances. It serves as an inexhaustible source of information and knowledge about everything that people can look for. It represents an extremely rich source of information of various kinds, forms, content, veracity, prices and quality. Based on the viewpoint of relationship between using the Internet and users' psychological behaviors, the addicts often feel lonely, tend to play violent games, and have a high tendency to suffer from depression. Several studies have reviewed the relationship among the Internet addiction and adolescents' psychological characteristics including depression. The authors report that there are a number of emotional factors which may be related to college students' internet addiction (Kandell, 1998). Among these factors the most remarkable are depression.

It can be considered as the biggest market of goods, information and services. (Zaeok, and Zaekova, 2008). With the number of Internet users increasing, more and more studies had been conducted with regard to the excessive use of the Internet. A small percentage of the online population have reported problems such as neglect of academic responsibility, work, domestic responsibilities, disruption of relationships, social isolation, and financial problems due to their Internet use. There are noticeable differences between normal internet usage and addicted / problematic internet usage (Aboujaoude, 2010). Normal users of internet use this technology for their daily needs and/or other necessities within reason (Kesici and Sahin, 2009), they can control themselves while using it (Davis, 2000), and they show normal behaviors when they don't have access to internet (DiNicola, 2004).

\section{REVIEW OF LITERATURE}

Internet is being widely used all around the world. The number of users is increasing day by day. Previous studies perceived the internet as having an overall negative effect on their daily lives and a break in the individual's psychological wellbeing. These studies defined wellbeing in the concept of mental illness and distress such loneliness and depression (Whang, Lee, \& Chang, 2003); current mental health treatments and behavioral difficulties (Mannell, Zuzanek, \& Aronson, 2013); impulsivity, sensation and novelty-seeking, social isolation (Young \& Roger, 1998) and sometimes enhanced levels of aggression (Chou, Condron, \& Belland, 2005). Chou and Hsiao (2000) investigated students' self-assessment of their Internet use and its impact on their lives. They found that those deemed Internet addicts reported more negative consequences on their studies and daily routines than did those deemed non-addicts. It is characterized by excessive and poorly controlled preoccupation or behaviors regarding the computer use and internet access that's lead to disorder (Martha, 2008). There are different types of internet addiction; web surfer, pornography, chatting and video games characterized by dry eyes, 
headache, sleep disturbance, neglect of family, problems with school or job etc.(ASAM, 2012). The people addicted to internet face physical side effects like sleep disturbance, back strain, eye strain, etc. Such persons also experiences family, academic and social problems (ASAM, 2012). A few empirical studies have examined the stereotype of the excessive Internet user-males in their late teens, as discussed in Griffiths (1998). Scherer (1997) reported that dependent Internet users included a significantly larger proportion of men to women (71\% men and 29\% women, respectively). Similar results were reported by Morahan-Martin and Schumacher (2000) that males were more likely to be pathological internet users than females.

There is also found a significant relationship between anxiety and depression in childhood with internet addiction in adolescent. Clinicians should consider depression during childhood to prevent internet addiction (Cho \& shin, 2013). Job engagement of mothers was significantly associated with students' internet addiction, and the least rate of addiction was observed when the mother was a housewife (Ahmadi, 2014). Several studies have reported gender differences in internet usage. Studies indicate that the use of computers and the internet differs between men and women. Weiser (2000) gave an extensive review and executed a study on gender differences in internet use patterns and internet application preferences in a sample of 1190 surveys. He concluded that there were numerous gender differences in preferences for specific Internet applications. Results had shown that men use the internet mainly for purposes related to entertainment and leisure, whereas women use it primarily for interpersonal communication and educational assistance. Male students are generally considered more experienced in programming and computer games than females. Also male students report having had more encouragement from parents and friends previously, in contrast to women, who might have been discouraged from using modern technologies (Busch, 1995). Papastergiou and Solomonidou (2005) mention that boys have more opportunities to access the Internet and use the Internet for entertainment and Web page creation than girls do, with no other differences in other activities.

\section{HYPOTHESES}

- Male and female students will differ significantly in internet addiction

- Internet addiction and depression will be positively related

\section{Sample}

The sample of the study is selected from different schools of Ranchi. There were 100 male and 100 female respondents of the age group 14 to 17 years. All of these belong to middle socioeconomic status.

\section{Tools}

- Young's Internet Addiction Test (IAT) - This was adapted to evaluate the respondents' level of internet addiction. It consists of 20 questions wherein each item is scored using a fivepoint Likert scale. It covers the degree to which internet use affect daily routine, social life, productivity, sleeping pattern and feeling. The instrument has exhibited good psychometric 
properties in previous researches. The marking for this questionnaire ranges from 20-100, the higher the marks the greater dependence on the internet is. It is evaluated as: 20 to 49 - normal internet users, 50 to 69 - addicted internet users and 70 to 100 - severely addicted internet users.

- Beck Depression Inventory (BDI, 1961) - BDI is a self-report measure of depression, consisting 21 items that assess the severity of affective, behavioural, cognitive and somatic symptoms of depression. Each item is scored on a 3 - point scale. It comprised of 20 items as its one item having sexual connotation was dropped, so score range of BDI is 0-60 and construct validity is 0.84 .

\section{RESULT AND DISCUSSION}

Table-1 Mean scores of boys and girls group on internet addiction.

\begin{tabular}{|l|l|l|l|l|l|l|}
\hline Groups & N & Mean & SDs & MD & t & P value \\
\hline Males & 100 & 61.98 & 16.92 & 13.02 & 5.92 & 0.01 \\
\hline Females & 100 & 48.96 & 14.18 & & & \\
\hline
\end{tabular}

Figure 1: Mean scores of male and female on internet addiction.

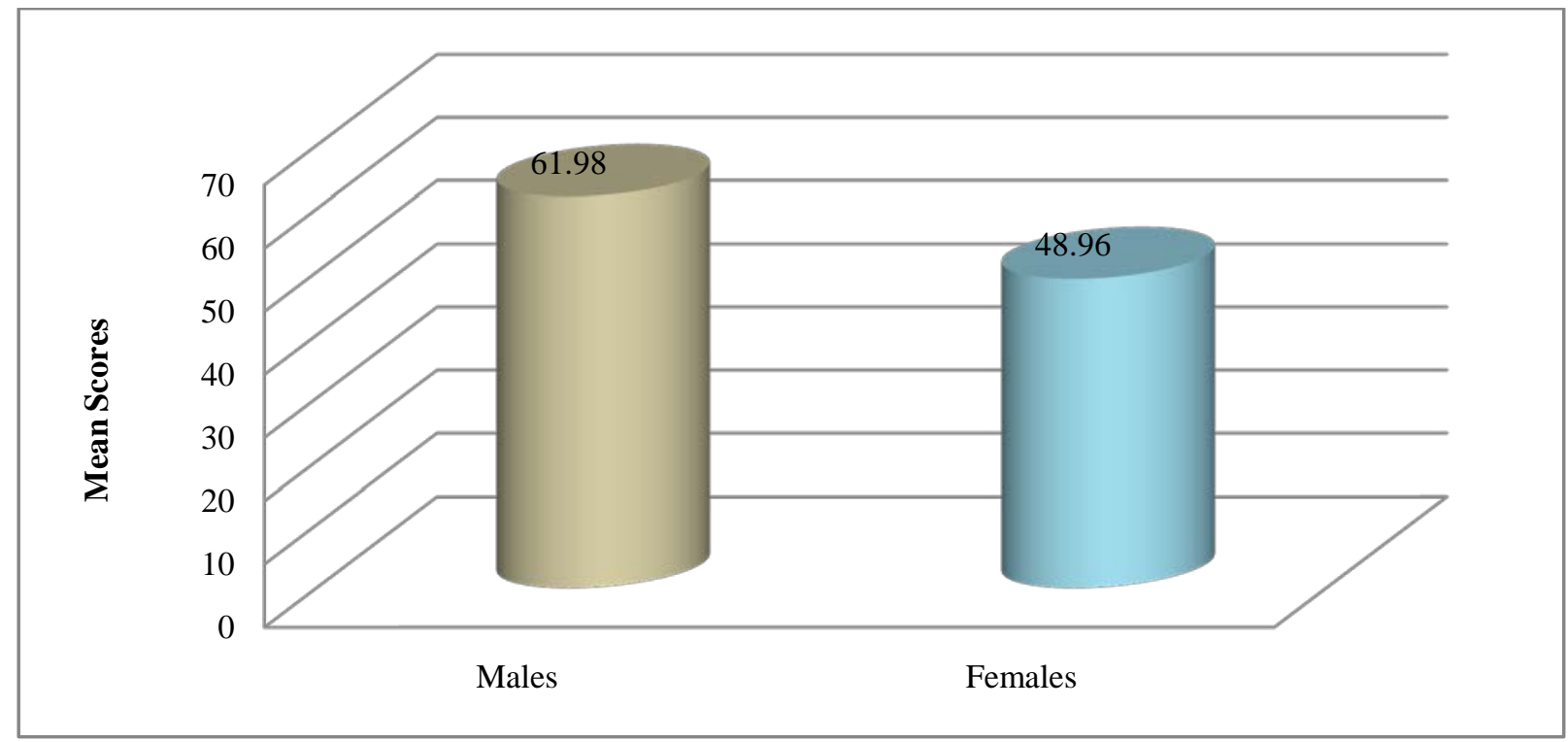

\section{According to the table - 1and figure - 1}

Males are found to be more addicted to the internet than females. As expected, male adolescents were found to have higher levels of internet addiction as compared to their female counterpart. It may be because of comparatively easy excess to internet of male students than female students. Hence, the hypothesis male and female students will differ significantly in internet addiction was accepted. This provides support to the findings of Sato (2009) and Beutel (2011) utilizing teenage population for the comparison on gender difference on internet 
addiction. Scherer (1997) suggested that dependent internet users included a large proportion of men as compared to women.

Table-2 Relationship between Internet addiction and Depression

$(\mathrm{N}=200)$

\begin{tabular}{|l|l|l|}
\hline & \multicolumn{1}{|c|}{ Depression } & P value \\
\hline Internet addiction & .58741 & Significant at 0.01 \\
\hline
\end{tabular}

When Table 2 was examined, it was seen that there were significant correlations between internet addiction and depression. The aim of this study was to investigate the relationships between internet addiction and depression. This finding suggests that higher levels of internet use are associated with higher level of depression. The exact cause of the relationship between depression and internet addiction is not known. Perhaps depression, as a mental impairment, predisposes the individual to suffer from the Internet addiction. Some people use internet in order to reduce their depression so that Internet may provide an alternative to a life without joy for depressed ones. Similarly, depression may occur as a result of internet addiction, it means that people who are addicted to the internet, experience the negative consequences such as depression, and this subject requires further studies.

\section{CONCLUSION}

- Male students were found more internet addicted than female students.

- Internet addiction and depression were positively related.

\section{REFERENCES}

Aboujaoude, E. (2010). Problematic Internet use: an overview. World Psychiatry, 9(2), 85-90.

Ahmadi, K. (2014). Internet addiction among Iranian adolescents: a nationwide study. Acta Med Iran. 52(6):467-72.

Beutel, M. E. (2011). Regular and Problematic Leisure-Time Internet Use in the Community: Results from a German Population-Based Survey. Cyber Psychology, Behavior, and Social Networking, 14, 291-296.

Busch, T. (1995). 'Gender differences in self-efficacy and attitudes towards computers', Journal of Educational Computing Research, 12, 147-158.

Byun, S., Ruffini, C., Mills, J.E., Douglas, A.C., Niang, M., Stepchenkova, S., Lee, S.K., Loutfi, J., Lee, J-K., Atallah, M., Blanton, M. (2009). 'Internet Addiction: Metasynthesis of 1996-2006. Quantitative Research’, Cyber Psychology \& Behavior, 12, pp. 203-207.

Cho, C, Sung Z, Shin, L, Lim, P and Shin, R. (2013). Does psychopathology in childhood predict internet addiction in male adolescents? Child Psychiatry Hum Dev. 44(4):54955.doi:10.1007/s10578-012-0348-4. 
Chou, C and Hsiao, M. C. (2000). Internet addiction, usage, gratifications, and pleasure experience — The Taiwan college students’ case. Comput. Educ. 35(1): 65-80.

Davis, D. (Ed.). (2000). The consumer revolution in urban China (Studies on China. 22. Berkeley: University of California Press

DiNicola, M. D. (2004). Pathological Internet use among college students: The prevalence of pathological Internet use and its correlates. Dissertation Abstracts International, 65 (05), 1675. Retrieved January 18, 2010, from ProQuest Digital Dissertations database (UMI No. AAT 3133723).

Greenfield, D. N., (2000). Psychological characteristics of compulsive internet use: A preliminary analysis. Cyber Psychology \& Behavior, 5, 403-412.

Griffiths, M. D. (1998). Internet addiction: Does it really exist? In Gackenbach, J. (ed.), Psychology and the Internet: Intrapersonal, Interpersonal, and Transpersonal Implications, Academic Press, New York.

Kandell, J. J., 1998. Internet addiction on campus: The vulnerability of college students. Cyber Psychology \& Behavior, 1, 11-17.

Kesici, S and Sahin, I. (2009). A comparative study of uses of the internet among college students with and without internet addiction. Psychological Reports, 105, 1103-1112.

Martha, A \& Donald, C. (2008). Internet addiction: Definition, assessment, epidemiology and clinical management.CNS Drugs (impact factor: 4.8). 22(5):353-65.

Morahan-Martin J, Schumacher. P. (2000). Incidence and correlates of pathological Internet use among college students. Comput. Hum. Behav. 16:13-29.

Nalwa, K., \& Anand, A. (2003). Internet addiction in students: A cause of concern. Cyber Psychology \& Behavior, 66, 653-656.

Papastergiou, M., Solomonidou, C. (2005). 'Gender issues in Internet access and favouriteInternet activities among Greek high school pupils inside and outside school', Computers \& Education, 44, pp. 377-393.

Sato, T. (2009). Internet Addiction among Students: Prevalence and Psychological Problems in Japan.

Scherer, K. (1997). College life online: Healthy and unhealthy Internet use. J. College Stud.Dev. 38(6): 655-665.

Weiser, E.B. (2000). 'Gender Differences in Internet Use Patterns and Internet Application Preferences: A Two-Sample Comparison’, Cyber Psychology \& Behavior, 3, 167-178.

Widyanto, L., Griffiths, M. (2006). 'Internet Addiction': A Critical Review’, International Journal of Mental Health and Addiction, 4, 31-51.

Yapici, I and Akbayin, H. (2012) High School Students’ Views on Blended Learning. Turkish

Zaeok, L. and Zaekova, Z. (2008). Internet as a Tool to Educate Managerial Staff at Schools. The New Educational Review, 16, 3-4. 